\title{
Deber de Vigilancia y Programas de Cumplimiento
}

Rolando Márquez Cisneros

Abogado por la Universidad de Piura. Magíster en Ciencias Jurídicas Avanzadas por la Universitat Pompeu Fabra. Magíster en Derecho Penal por la Pontificia Universidad Católica del Perú.

Doctor en Derecho por la Universitat Pompeu Fabra. Profesor de la Maestría en Derecho Penal de la Universidad de San Martín de Porres. Profesor de la Academia Nacional de la Magistratura.

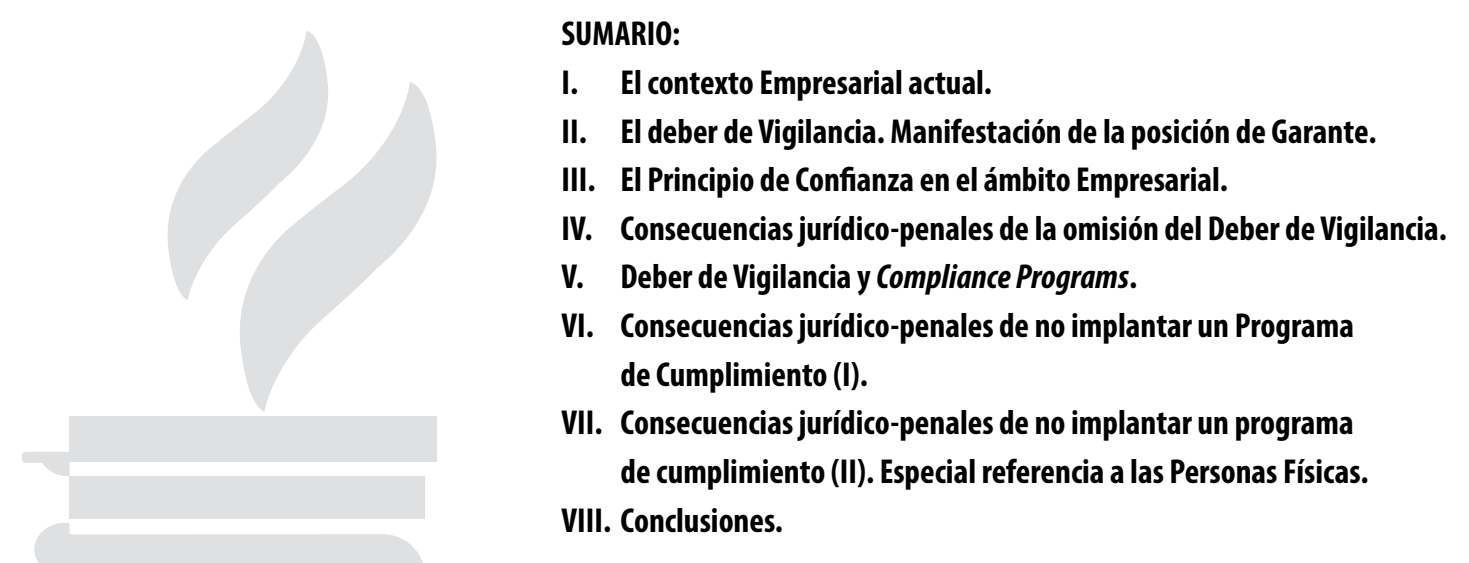

* El artículo fue recibido con fecha 01-08-18. 


\section{RESUMEN:}

En la actualidad, la confluencia de una diversidad de factores ha generado que los directivos de las empresas estén expuestos, cada vez más, a los riesgos propios de la actividad corporativa. En este contexto, adquiere especial relevancia el deber de vigilancia que aquéllos ostentan sobre los actos de los subordinados. En la medida en que la organización empresarial progresivamente se torna más compleja, surge y se impone la necesidad de delegar en un tercero -el Compliance officer- la ejecución del deber de vigilancia. La cuestión que emerge con ello es si este delegado de vigilancia puede ser responsabilizado penalmente por omitir la función que se le ha asignado y, si esto fuese posible, cuál es el fundamento de esa responsabilidad.

Palabras clave: Posición de garante, deber de vigilancia, omisión, Compliance, oficial de cumplimiento.

\footnotetext{
ABSTRACT:

Nowadays, directors are more and more exposed every day to the risks of corporate activity due to the confluence of diverse factors. Consequently, he duty of care over subordinates' acts has become particularly relevant. As business organization becomes more complex progressively, the need to delegate the execution of the duty of care to a third party -the Compliance officer- develops. What comes up with this is that if this third party, who has been delegated the duty of care, can be criminally responsible for omitting to carry out the assigned duty, and what is the basis for that responsibility, if applicable.

Keywords: guarantor position, duty of care, omission, Compliance, Compliance officer.
}

\section{EL CONTEXTO EMPRESARIAL ACTUAL}

La sociedad actual, que en el Derecho penal es catalogada como "Sociedad del riesgo"' teriza, entre otros rasgos, por la aparición de una serie de normas que regulan, si no todos, casi todos los ámbitos de la actividad humana. Uno de estos ámbitos es el de la economía. En efecto, las empresas cada vez más están obligadas a cumplir un sinnúmero de disposiciones - muchas veces contradictorios - previstas en normas de distinta jerarquía y con cierto grado de complejidad.

En este contexto, en la medida en que muchas de estas disposiciones regulan aspectos que solo pueden ser comprendidos por determinadas personas -el alto grado de espe- cialización es otra de las características de la sociedad moderna-, se puede afirmar que concurren situaciones en las que el empresario termina adoptando decisiones prácticamente con desconocimiento del ámbito en el que ha decidido. Ello, sin embargo, no lo exime de responsabilidad penal, si en el caso concreto se demuestra que pudo evitar el comportamiento riesgoso o lesivo ${ }^{2}$.

La responsabilidad penal del empresario por no evitar se enmarca, pues, en la nueva lógica del Derecho penal, que no espera ya la materialización de una lesión para entonces reaccionar sino que ahora adelanta las barreras de protección a momentos previos a la misma ${ }^{3}$, de tal manera que el legislador actual recurre

1. Sobre los principales rasgos del Derecho penal de la Sociedad del riesgo, Cfr. FEIJOO SÁNCHEZ, Bernardo José. "Sobre la administrativización del Derecho penal en la Sociedad del riesgo. Un apunte sobre la política criminal a principios del siglo XXI". En: Derecho y justicia penal en el siglo XXI: liber amicorum en homenaje al profesor Antonio González-Cuéllar García. Madrid: 2006, pp. 147 y ss.

2. De igual parecer, BACIGALUPO, Enrique. Compliance y Derecho penal. Prevención de la responsabilidad penal de directivos y de empresas. Buenos Aires: 2012, p. 31.

3. Evidentemente, la nueva lógica del Derecho penal influye también en la labor del jurista, que ahora ha de conceder particular importancia al asesoramiento preventivo. 
cada vez más a la técnica de los delitos de peligro - especialmente abstracto-, más aún en el ámbito de la economía, sector en el que la producción de una lesión a los objetos jurídicos protegidos, incluso la generación de un riesgo para los mismos, conlleva incalculables consecuencias adversas para un gran número indeterminado de personas.

En este orden de ideas, puesto que en el contexto actual las empresas son cada vez más fuentes generadoras de riesgos - cuya magnitud depende de su tamaño y del rubro de su actividad-, conviene implantar un sistema de control preventivo cuya función primaria radica en evitar el surgimiento de riegos que puedan dar lugar a responsabilidad penal, es decir, un sistema que controle el cumplimiento de la legalidad en el ámbito empresarial, un sistema que no es otra cosa que el llamado Compliance program.

Pues bien, en la medida en que se habla de establecer mecanismos de control, surge la interrogante de si los directivos deben responder penalmente por no haber evitado, por falta de control, los delitos cometidos por sus subordinados en el ejercicio de sus funciones. Esta cuestión es especialmente importante si se tiene en cuenta que, en el ámbito empresarial, la tendencia actual es desplazar la responsabilidad penal hacia arriba, es decir, hacia los superiores jerárquicos ${ }^{4}$.

\section{EL DEBER DE VIGILANCIA. MANIFESTACIÓN DE LA POSICIÓN DE GARANTE}

La convivencia en sociedad, y por tanto su buen funcionamiento, exige que no todo sea competencia de todos. Un punto de vista dis- tinto terminaría por obstaculizar la consecución de objetivos comunes y con ello por paralizar la sociedad. En este sentido, frente a las teorías de la causalidad, en cuya virtud la responsabilidad penal se extiende a todos quienes de alguna $u$ otra manera estuviesen causalmente vinculados con el resultado, la teoría de la imputación objetiva plantea atribuir responsabilidad penal únicamente a quien no ha obrado dentro de los parámetros establecidos por el rol, general y específico, que la sociedad le asigna.

En este orden de ideas, los superiores jerárquicos - el administrador, el socio de la empresa, en buena cuenta, el empresario- son garantes respecto de la conducta de sus subordinados, es decir, tienen el deber de evitar que el comportamiento de éstos, en el ámbito en el que se realiza la concreta actividad empresarial, acarree la afectación de bienes jurídicos. Las objeciones a la existencia de ese deber, basadas normalmente en la autorresponsabilidad del empleado, no han tenido mayor eco en la doctrina ${ }^{5}$.

De esta manera, en el escenario de asignación de roles se acepta habitualmente que el deber de garante del directivo incluye deberes de vigilancia. Pese a ello, la existencia de estos últimos puede terminar no siendo clara pues la complejidad organizativa de la actividad empresarial moderna determina que en la práctica tenga lugar una delegación de competencias cuyo fundamento es la imprescindible división de tareas. En efecto, el deber de garantía es, en general, delegable y el deber específico de vigilancia del superior también lo es. Ahora bien, el instituto de la delegación no elimina la posición de garante del superior delegante

\section{Cfr. BACIGALUPO, Enrique. Op. Cit., pp. 51 y 148.}

5. Según DOPICO GÓMEZ-ALLER, Jacobo. "Posición de garante del Compliance officer por infracción del deber de control: una aproximación tópica". En: ARROYO ZAPATERO, Luis y NIETO MARTÍN, Adán (Dirs.). El Derecho penal económico en la era Compliance. Valencia: 2013, pp. 171, en el plano dogmático, el argumento de la autorresponsabilidad a lo máximo a lo que puede aspirar es a discutir si quien omite impedir el delito debe responder como autor o como partícipe por omisión. Por lo demás, no es que aquí se niegue la autorresponsabilidad de los dependientes, sino que ésta, considero, resulta insuficiente como argumento para eximir de responsabilidad al superior: no se puede afirmar que éste no debe vigilar porque el subordinado es autorresponsable. 
sino que la transfiere y transforma ${ }^{6}$. La transfiere porque con la delegación surge una nueva posición de garante: la del delegado. La transforma porque con la delegación la posición de garantía del delegante se convierte en residual, es decir, ya no le atañe controlar directamente las fuentes de riesgo que se encuentran en el ámbito de competencia del delegado; pero sí le corresponden, entre otros deberes, el de seleccionar correctamente al delegado, instruirlo e informarlo ${ }^{7}$, suministrarle los medios necesarios para el cumplimento de sus funciones y vigilar su actividad ${ }^{8}$.

\section{EL PRINCIPIO DE CONFIANZA EN EL ÁMBITO EMPRESARIAL}

El superior jerárquico, según señalé al finalizar el párrafo anterior, tiene siempre el deber de seleccionar correctamente a sus subordinados, ya de modo directo, ya a través de empresas especializadas en selección de personal.

Evidentemente, solo si se han incumplido las actividades previas que demanda una correcta selección - publicidad de la oferta laboral, evaluación curricular, no acreditación de capacidades, establecimiento de criterios de selección coherentes con la probabilidad de infracción, entre otros-, entonces existirá un deber de vigilancia permanente del superior sobre el subordinado seleccionado. En esta línea, cuanto menor sea la experiencia y la preparación del dependiente, entonces mayor será el deber de vigilancia del superior $y$, en consecuencia, menor será la protección que dispensa el principio de confianza9. En caso contrario, esto es, si el subordinado ha sido elegido tras un proceso de selección correctamente ejecutado por el superior jerárquico, entonces éste está jurídicamente facultado para confiar en que aquél, en el desempeño de su cargo, se comportará conforme a Derecho. En este último caso, el superior jerárquico estará amparado, pues, por el principio de confianza. Afirmar un punto de vista distinto - es decir, que en el supuesto de incorrecta selección el superior tiene el deber de vigilar al subordinado elegido y que también tiene ese deber en el supuesto de una correcta selección- conlleva la incongruencia de no poder determinar entonces cuál es la diferencia, a nivel de consecuencias jurídicas, entre cumplir e incumplir las tareas previas que demanda un proceso de selección. La función orientadora del Derecho penal —educativa, si se quiere- se desdibujaría si no se establecen motivos para cumplir las normas y evitar con ello la imposición de sanciones.

En este sentido, conforme con el principio de confianza, nacido en el ámbito del tráfico rodado pero aplicable a todos los ámbitos en que confluyen deberes plurales de actua-

6. Cfr., SILVA SÁNCHEZ, Jesús María. Fundamentos del Derecho penal de la Empresa. Madrid: 2013, p. 157; también BACIGALUPO, Enrique. Op. Cit., p. 152; LASCURAÍN SÁNCHEZ, Juan Antonio. "Fundamento y límites del deber de garantía del empresario". En: Hacia un Derecho penal económico europeo. Jornadas en honor del profesor Klaus Tiedemann. Madrid: 1995, p. 218 y DOPICO GÓMEZ-ALLER. El Derecho penal económico en la era Compliance. p. 172.

7. En este sentido, GARCÍA CAVERO, Percy. Criminal Compliance. Lima: 2014, pp. 36 y 42 . Afirma que una adecuada selección del personal no exonera de la necesidad de capacitar suficientemente al trabajador en la actividad asignada al interior de la empresa, siendo razonable que éste reciba capacitación según la probabilidad de infracción legal a que está expuesto.

8. Distintos argumentos se han esbozado para justificar el deber de vigilancia del superior; así, la mayor cantidad de información que éste posee, el control que tiene sobre todos los niveles de la organización, etc.

9. Este parece ser también el punto de vista de GARCÍA CAVERO, Percy. Criminal Compliance. Lima: 2014, p. 36. Cuando afirma que si el subordinado no se ajusta a los parámetros exigidos en el cumplimiento del encargo, entonces al superior corresponderá intervenir para remediar las irregularidades. 
ción ${ }^{10}$, un sujeto que actúa de forma correcta en su ámbito de organización puede asumir válidamente que otro también lo hará en el suyo - circunstancia que genera una organización más racional de la búsqueda del interés común-11, salvo que tenga razonables indicios de que éste va a actuar de modo incorrecto, en cuyo caso debe intervenir para evitar el resultado lesivo indeseado.

Si bien se mira, el principio de confianza, al imponer el deber de estar atento para captar los eventuales indicios de un comportamiento incorrecto de otro sujeto; impone, en estricto, un deber de evitar resultados lesivos en ámbitos de organización ajenos, es decir, el principio de confianza presupone la existencia de deberes de garantía - deberes especiales recíprocos de corrección- más allá del propio ámbito de organización, presupone una vinculación entre esferas de organización prima facie separadas ${ }^{12}$.

En este orden de ideas, la única forma de activar ese deber preexistente, de modo tal que se pueda luego imputar el haberlo infringido, es que el sujeto, a través de serios indicios, haya conocido o podido conocer el comportamiento incorrecto del otro sujeto. A partir de este dato se puede concluir que lo propio de las relaciones gobernadas por el principio de confianza es que, si bien el sujeto tiene el deber de evitar resultados lesivos producidos en el ámbito de organización de un tercero, no tiene el deber de buscar de forma permanente el conocimiento sobre la forma en que está comportándose el otro sujeto. La ausencia de este deber distingue las relaciones gobernadas por el principio de confianza de las que son regidas por el principio de desconfianza, relaciones estas últimas en las que sí existe el deber de buscar información sobre la forma en que un tercero está administrando su ámbito de organización. En las relaciones presididas por el principio de desconfianza existe, pues, el deber de supervisar, controlar y vigilar el comportamiento de terceros ${ }^{13}$.

Aplicado esto último a las relaciones en el ámbito empresarial, no existen razones válidas que justifiquen por qué el directivo de una empresa ha de desconfiar de sus subordinados, mandos medios, si estos, además de ser sujetos autorresponsables, han sido correctamente seleccionados; y por qué estos últimos han de desconfiar a su vez de sus subordinados, también autorresponsables y correctamente seleccionados.

Afirmar que el directivo debe desconfiar y por tanto vigilar al mando medio y que éste a su vez debe desconfiar y vigilar a sus subordinados implica, en la práctica, instaurar un sistema de múltiples controles de riesgos. Éstos ya no solo se encontrarán bajo el control del sujeto directamente encargado de ello, sino que también estarán controlados por otros sujetos, los superiores jerárquicos, a quienes se les impone el deber de supervisar y controlar al sujeto directamente encargado. La principal objeción a un sistema de esta naturaleza es que termina imputando responsabilidad penal a sujetos ubicados en los eslabones superiores de la estructura empresarial, por el mero hecho de estar ahí ubicados, es decir, termina instaurando un sistema de responsabilidad objetiva, proscrita en el Derecho penal - esto al margen de las consecuencias negativas para la colectividad: si el directivo de una empresa tuviese que

10. En este sentido, CANCIO MELIÁ, Manuel. Líneas básicas de la teoría de la imputación objetiva. Mendoza: 2001, p. 105. De igual forma, GARCÍA CAVERO, Percy. Derecho penal económico. Parte general, Tomo I, Segunda Edición. Lima: 2007, p. 372, entiende que el principio de confianza frente a terceros se exige especialmente en organizaciones empresariales.

11. Cfr. FEIJOO SÁNCHEZ, Bernardo José. Imputación objetiva en Derecho penal. Lima: 2002, p. 297.

12. SILVA SÁNCHEZ, Jesús María. Fundamentos del Derecho penal de la Empresa. Madrid: 2013, p. 166.

13. Ibíd., p. 168. 
desconfiar permanentemente de sus dependientes, entonces la producción se paralizaría y con ello también la sociedad-.

En cualquier caso, parece ser que la reducción o -incluso- la anulación de los frenos inhibitorios, consecuencias inherentes a las actuaciones en grupo, justifican la existencia en el superior de deberes de vigilancia. En efecto, el profesor Silva Sánchez explica que el fundamento de tales deberes de vigilancia en el ámbito empresarial podría encontrarse en el potencial criminógeno de ciertas dinámicas de grupo a las que se añaden otras razones propias de la organización empresarial como las concepciones erradas de la lealtad y la solidaridad, el orientarse únicamente al lucro, la tendencia a la desorganización progresiva, la infravaloración de los riesgos, etc ${ }^{14}$. Todo esto, según el citado autor, puede determinar que los subordinados autorresponsables y correctamente seleccionados se comporten, pese a todo, con una deficiencia tal que les impida primero percibir y luego controlar los riesgos. Deficiencias ante las que el superior jerárquico debería actuar mediante la correspondiente vigilancia que de este modo se convierte ya en un deber ${ }^{15}$.

Ahora bien, la ejecución del deber de vigilancia no significa revisar todos los actos del subordinado - esto haría inútil la delegación-, tampoco significa que el superior deba esperar a tener indicios de una conducta incorrecta para entonces recién reaccionar - esto es lo propio de la relaciones gobernadas por el principio de confianza y el deber de vigilancia, según se dijo, presupone la desconfianza-. Siendo esto así, el deber de vigilancia puede ejecutarse, por ejemplo, instaurando sistemas de inspección, estableciendo procedimientos de remisión de información o creando un órgano específico para esa actividad. Una vez que se hayan implantado estos sistemas de vigilancia, el superior jerárquico estará ya amparado por el principio de confianza, es decir, la desconfianza inicial, por la que el superior debía vigilar, pasa a ser reemplazada por la confianza.

\section{CONSECUENCIAS JURÍDICO-PENALES DE LA OMISIÓN DEL DEBER DE VIGILANCIA}

La omisión del deber de vigilancia no es punible en sí misma. En este sentido, solo es posible aplicar una pena al vigilante si, además de haber omitido dicho deber, el vigilado inicia la ejecución del delito - si se trata de un delito doloso - o lo llega a consumar - si se trata de un delito imprudente-. La sanción al superior por omitir su deber de vigilancia está marcada, pues, por su carácter accesorio ${ }^{16}$.

Distintas soluciones pueden plantearse respecto de las consecuencias que acarrea la omisión del deber de vigilancia. Así, se podría entender que la omisión de dicho deber genera, en caso se produzca la lesión, una imputación de esta al delegante-vigilante a título de autoría en comisión por omisión. Esta solución puede ser articulada por quienes consideran que todos los delitos de comisión por omisión son delitos de infracción de un deber. En consecuencia, como no es posible establecer diferencia alguna entre los garantes que omiten evitar un resultado lesivo, pues todos ellos infringen su deber, todos deben ser considerados autores. En otras palabras, según este planteamiento, el superior jerárquico que no

14. GARCÍA CAVERO, Percy. Criminal Compliance. Lima: 2014, p. 24. Señala que si bien parece obvio que las personas, tanto naturales como jurídicas, deban abstenerse de realizar conductas prohibidas, el cumplimiento de la ley no es fácil de conseguir en empresas complejamente organizadas pues la influencia de la cultura corporativa puede llevar a que los miembros de la empresa terminen actuando al margen de la ley.

15. SILVA SÁNCHEZ, Jesús María. Fundamentos del Derecho penal de la Empresa. Madrid: 2013, p. 171.

16. Cfr. Ibíd., p. 175. 
impidió la comisión del delito del subordinado, porque dolosamente omitió su deber de vigilancia, también será autor de dicho ilícito ${ }^{17}$.

Sin embargo, este planteamiento, que considera como autor al superior omitente, merece una diferenciación. Si lo no evitado es un resultado lesivo para la propia empresa, entonces la imputación al superior a título de autor, por no haber evitado debido a un déficit de vigilancia, puede no revestir cuestionamiento alguno en la medida en que podría afirmarse que el superior-vigilante tiene un deber especial de lealtad a la empresa que ha infringido ${ }^{18}$. En cambio, si la lesión es a terceros, resulta cuestionable imputar este resultado a título de autor al superior, por haber omitido la vigilancia, porque no existe un deber de lealtad de este respeto de terceros ajenos a la empresa. Dicho de otra manera, no es posible considerar siempre como autor al superior que omite pues no basta infringir el deber especial ${ }^{19}$.

En este orden de ideas, Silva Sánchez plantea considerar la omisión de vigilancia en el ámbito de la infracción de deberes de organización. Así, para él, si el superior retuvo la competencia de controlar directamente el riesgo que generó el resultado, entonces su omisión de vigilancia - y de corrección directa o indirecta a través de órdenes - puede dar lugar a una autoría en comisión por omisión. En cambio, si el superior no ha retenido dicha competencia, como tiene el deber de instar al vigilado a que neutralice directamente el riesgo dentro de su propia esfera de competencia, entonces lo más razonable es calificar su infracción como participación por omisión ${ }^{20}$. Una participación omisiva del superior que, por lo demás, es admisible tanto en los delitos de acción como en los delitos de omisión. Un ejemplo de esta última modalidad puede ser el caso de un Gerente de Operaciones Ambientales que omite el deber de controlar y vigilar a sus subordinados que, finalizada la actividad extractiva, omiten a su vez cumplir el plan de cierre progresivo de minas.

Desde mi punto de vista, a partir de lo que exige la comisión por omisión, considero, conforme lo señala De Vicente Remesal, que el criterio más razonable para afirmar la autoría es el de la creación o incremento determinante del riesgo de lesión del bien jurídico por la propia omisión de vigilancia del directivo. Por su parte, la participación por omisión - participación en comisión por omisión- tendrá lugar cuando la propia omisión de vigilancia favorezca la afectación del bien jurídico por parte del autor, es decir, cuando la omisión del deber de vigilar aumente el riesgo de producción de esa afectación pero no de un modo determinante; en otras palabras, cuando la propia omisión constituya una aportación suficientemente relevante al punto que en efecto posibilite, favorezca o facilite o suponga una remoción de obstáculos a la conducta del autor - equivalencia respecto del cooperador activo-, no bastando que la omisión de ese

17. Del mismo parecer es BACIGALUPO, Enrique. Op. Cit., p. 149.

18. Cfr. SILVA SÁNCHEZ, Jesús María. Fundamentos del Derecho penal de la Empresa. Madrid: 2013, p. 177.

19. Para ROXIN, Claus. Strafrecht. Allgemeiner Teil, Tomo II, Besondere Erscheinungsformen der Straftat. Múnich: 2003, $\S 31, \mathrm{~nm}$. 140. El garante omitente es siempre autor porque los delitos de omisión son delitos de infracción de deber. No obstante, admite la posibilidad de que, si la intervención del garante es activa, en vez de omisiva, no necesariamente esta intervención da lugar a autoría.

20. Cfr. SILVA SÁNCHEZ, Jesús María. Fundamentos del Derecho penal de la Empresa. Madrid: 2013, pp. 178 y ss. La teoría del dominio del hecho, por su parte, también puede proveer de fundamento a la calificación como partícipe del superior que omite su deber de vigilancia, en la medida en que él no domina el devenir del suceso necesario para la autoría. 
deber suponga una mera no dificultad o no interposición de obstáculos al hecho del autor ${ }^{21}$.

El planteamiento de De Vicente Remesal, considero, no se opone al propuesto por Silva Sánchez pues si el superior retiene la competencia de controlar directamente el riesgo, entonces la omisión de la vigilancia a su cargo puede entenderse como una creación o incremento determinante del riesgo que da lugar a la autoría. En cambio, si el superior no ha retenido dicha competencia, pero tiene el deber de instar al vigilado a que neutralice directamente el riesgo; entonces la omisión de este deber puede entenderse como un favorecimiento al hecho del autor que da lugar a la participación por omisión del superior.

\section{DEBER DE VIGILANCIA Y COMPLIANCE PROGRAMS}

Es importante destacar que las actividades con las que se puede satisfacer el deber de vigilancia no son absolutamente nuevas. En estricto, los mecanismos para ejercer el control interno dirigido a evitar infracciones en el ámbito empresarial son conocidos y ejecutados desde hace mucho tiempo, pero se restringían a ámbitos como la prevención de riesgos laborales o la prevención de delitos cometidos contra la empresa - por ejemplo, las medidas antifraude-. No obstante ello, los programas de cumplimiento normativo tienen un origen bastante reciente que, por lo demás, grafica la estrecha relación que existe entre éstos y los deberes de vigilancia.
En efecto, si se tiene en cuenta que los programas de cumplimiento surgen con la finalidad de asegurar la observancia de la ley en las actividades corporativas, propósito que busca ser materializado mediante dos funciones: una "principal" y otra "secundaria"; a saber: evitar la comisión de delitos y confirmar la vigencia de la normativa penal -en caso el delito no se haya evitado-, respectivamente, y que ambas funciones, pese a que en estricto corresponden al Estado ${ }^{22}$, se delegan a las empresas porque este, sobretodo en un mundo globalizado y altamente especializado, no tiene ya la capacidad para cumplirlas en el ámbito empresarial ${ }^{23}$, se concluye entonces que el Compliance program no es sino un mecanismo interno de vigilancia de la empresa. En otras palabras, Compliance significa autovigilancia ${ }^{24}$.

Esta autovigilancia de la empresa se manifiesta con más claridad aún desde la última década del siglo pasado, en que se ha ido consolidando como modelo de prevención de riesgos en el ámbito empresarial la denominada autorregulación regulada, en virtud de la cual la misma empresa fija internamente parámetros de actuación en concordancia con la legislación vigente.

Ahora bien, las medidas de autovigilancia de la empresa no agotan los programas de cumplimiento pues éstos también suelen incluir medidas orientadas a incentivar su observancia por parte de los miembros de la empresa; así, por ejemplo, pueden incluir algún tipo de reconoci-

21. DE VICENTE REMESAL, Javier. "Omisión del deber de vigilancia en la empresa: comisión por omisión y tipificación expresa del favorecimiento omisivo de delitos". En: GIMBERNAT ORDEIG, Enrique; GRACIA MARTíN, Luis; PEÑARANDA RAMOS, Enrique; RUEDA MARTíN, María Ángeles; SUÁREZ GONZÁLEZ, Carlos y Urquizo Olaechea, José (eds.). Dogmática del Derecho penal: Material y procesal y política criminal contemporáneas. Homenaje a Bernd Schünemann por su $70^{\circ}$ aniversario, Tomo II. Lima: 2014, pp. 14 y 27.

22. En este sentido, SIEBER, Ulrich. "Programas de Compliance en el Derecho penal de la empresa. Una nueva concepción para controlar la criminalidad económica". En: ARROYO ZAPATERO, Luis y NIETO MARTíN, Adán (Dirs.). El Derecho penal económico en la era Compliance. Valencia: 2013, p. 78, al resaltar la regulación autónoma de las empresas, denomina a ésta "Derecho sin Estado".

23. Del mismo parecer es GARCÍA CAVERO, Percy. Criminal Compliance. Lima: 2014, pp. 22 y ss. y 57 y ss.

24. Cfr. SILVA SÁNCHEZ, Jesús María. Fundamentos del Derecho penal de la Empresa. Madrid: 2013, p. 193. 
miento por la consecución de determinados objetivos. De esta manera, mediante la creación de un ambiente en el que la comisión de ilícitos sea la opción menos viable, los Compliance programs buscan consolidar una cultura de cumplimiento normativo en los miembros de la empresa, de tal forma que estos interioricen que la única manera de impulsar su crecimiento profesional no depende de las utilidades que por cualquier medio generen a la empresa sino del respeto a las normas correspondientes. De ahí que los programas de cumplimiento deban sustentarse en valores éticos que han de guiar luego la actuación de los miembros de la empresa ${ }^{25}$.

En consecuencia, conforme señala Silva Sánchez, la relación entre Compliance y deber de vigilancia jurídico-penal es una relación de género a especie. Esto porque, según indica, los programas de cumplimiento tienen un objetivo más amplio que el de evitar delitos: a saber, otros ilícitos jurídicos o éticos; además, porque buscan alcanzar dicho objetivo a través de mecanismos que van más allá de la mera imposición de deberes de vigilancia $y$, finalmente, porque la sola implantación formal de un programa de cumplimiento no significa que los administradores hayan cumplido automáticamente el deber de vigilancia ${ }^{26}$.

\section{CONSECUENCIAS JURÍDICO-PENALES DE NO IMPLANTAR UN PROGRAMA DE CUMPLIMIENTO (I)}

En nuestro país no existe un deber general impuesto a las empresas de instaurar en su interior un programa de cumplimiento normativo que garantice el respeto de la legislación penal. Esto significa entonces que el establecimiento de medidas orientadas a prevenir delitos es una decisión que corresponde exclusivamente a quienes dirigen la organización. Existen ámbitos concretos de actividad, no obstante, en los que, debido a su peculiar relevancia social lavado de activos, medioambiente y seguridad laboral-, el Estado impone al órgano de administración de la empresa el deber de gestionar los riesgos penales mediante la implantación de programas de cumplimiento que, además, han de incorporar necesariamente determinados elementos ${ }^{27}$.

En este orden de ideas, conforme lo señala García Cavero, el que una empresa eventualmente se proponga instaurar un programa de cumplimento depende del nivel de riesgo de comisión de delitos en la actividad empresarial, riesgo que a su vez depende del tamaño y del rubro de la empresa ${ }^{28}$. Así, no se puede negar la existencia de casos en los que al interior de la compañía se controla efectivamente a los subordinados pese a que en ésta no se ha instaurado formalmente un Compliance program.

Al margen de que, al menos desde una óptica legalista, no habría inconveniente en aceptar la concurrencia de responsabilidad penal en los casos en los que el órgano de administración incumple el deber de implantar un programa de cumplimiento -o implanta uno inadecuado o una vez implantado omite el deber de actualizarlo- pese a que el legislador se lo había impuesto — responsabilidad penal supeditada,

25. Sobre el particular, GARCÍA CAVERO, Percy. Criminal Compliance. Lima: 2014, p. 34. Señala que la orientación ética del comportamiento tiene la ventaja de ofrecer parámetros de decisión a los miembros de la empresa en aquellos ámbitos en los que la regulación legal no determina concretamente el curso correcto de la acción.

26. Cfr. SILVA SÁNCHEZ, Jesús María. Fundamentos del Derecho penal de la Empresa. Madrid: 2013, pp. 193 y ss.

27. Respecto de los sistemas de prevención de riesgos penales, existen tres modelos de regulación distintos, según los actores que participan en el proceso de formulación de los mecanismos internos de la empresa: la autorregulación, la co-regulación estatal y privada y la regulación netamente estatal. Para una explicación más detallada de estos modelos, Cfr. GARCÍA CAVERO, Percy. Criminal Compliance. Lima: 2014, pp. 13 y ss. y también SIEBER. El Derecho penal económico en la era Compliance. p. 77.

28. En el mismo sentido, GARCÍA CAVERO, Percy. Criminal Compliance. Lima: 2014, p. 28. 
claro está, a que el subordinado materialice el delito-, lo importante es determinar, primero, si el empresario tiene un deber de garantía de instaurar un programa de cumplimiento - $\mathrm{O}$ de modificar uno ineficaz o de actualizar uno obsoleto- $y$, segundo, si el incumplimiento de ese deber equivale a un incumplimiento del deber de vigilancia.

Si bien se mira, el deber de vigilancia del superior respecto de los subordinados, aunque puede incorporarse en un programa de cumplimiento, no es sino una manifestación propia de la relación de subordinación o de la delegación de funciones que tiene lugar al interior de la empresa. En efecto, como dije, la división de tareas hace que los deberes primarios del superior delegante pasen a la esfera de competencia del subordinado delegado, reteniendo aquél el deber de seleccionar correctamente a éste, instruirlo e informarlo, suministrarle los medios necesarios para el cumplimento de sus funciones $y$ vigilar su actividad. Dicho de otra forma, el Compliance, en definitiva, no crea estos deberes sino que, al ser evidentes, los reconoce con la finalidad de asegurar su observancia ${ }^{29}$. Por eso, el superior que omite implantar un Compliance program, pese a que despliega su actividad empresarial en un ámbito cuyas peculiaridades lo hacen necesario ex ante, puede ser pasible de una pena, si un subordinado comete un delito en el desempeño de sus funciones. Esto es así porque su omisión habrá significado, en ese caso, incumplir el deber de vigilancia.

En este orden de ideas, puede concluirse que, en aquellos ámbitos empresariales en los que existe un riesgo no insignificante de infracciones legales - bien por el tipo de actividad, bien por la dimensión de la compañía, bien por otra circunstancia-, la implantación de un Compliance program deviene en un deber jurídico impuesto al superior jerárquico, deber de cuyo cumplimiento se encarga también el Derecho penal.

Esto significa que, con relación a los Compliance programs, la responsabilidad penal individual del superior jerárquico, según ya adelanté, se plantea especialmente respecto de las conductas omisivas pues precisamente los deberes de vigilancia que le competen pueden ser satisfechos mediante la implantación de tales programas. En la medida en que de su posición de garante se derivan deberes de actuar para evitar lesiones a bienes jurídicos de terceros, la omisión de implantar un Compliance program, ahí donde resulta necesario, puede fundamentar la omisión punible del directivo ${ }^{30}$. Por el contrario, como el deber de vigilancia puede satisfacerse mediante la implantación de otros mecanismos alternativos a los Compliance programs, como según dije, no existe deber legal de adoptar estos últimos, en ámbitos empresariales no complejos la omisión del directivo de instaurar un Compliance program no significa una infracción de su deber de vigilancia, de ahí que en ese caso tal comportamiento no da lugar a responsabilidad penal ${ }^{31}$.

Cabe señalar que una vez implantado un programa de cumplimiento, eficaz ex ante, el directivo puede confiar en que sus subordinados adaptarán su comportamiento a los códigos de conducta que dicho programa incorpora, salvo

29. Cfr., Ibíd., p. 37. Sobre el particular, SILVA SÁNCHEZ, Jesús María. Fundamentos del Derecho penal de la Empresa. Madrid: 2013, p. 194. Entiende que la implantación de un Compliance program integra, entre otras medidas, la sistematización y procedimentalización formalizadas de un modelo de vigilancia de los superiores sobre los subordinados.

30. En el mismo sentido, SIEBER. El Derecho penal económico en la era Compliance. p. 83; también, GARCÍA CAVERO, Percy. Criminal Compliance. Lima: 2014, p. 101.

31. De ahí que, para lbíd., no es posible establecer una relación forzosa entre la ausencia de un programa de cumplimiento normativo y la infracción del deber de controlar los riesgos de la actividad empresarial. 
que tenga indicios fundados de que ese comportamiento correcto no tendrá lugar, situación en la que, por el contrario, tendrá el deber de vigilar a sus subordinados, deber de vigilancia cuyo cumplimiento en el caso concreto puede exigir, según dije, una actualización o una modificación del Compliance program implantado.

\section{CONSECUENCIAS JURÍDICO-PENALES DE NO IMPLANTAR UN PROGRAMA DE CUMPLIMIENTO (II). ESPECIAL REFERENCIA A LAS PERSONAS FÍSICAS}

En la medida en que un programa de cumplimiento, ex ante eficaz, busca principalmente prevenir delitos, la decisión de implantarlo, ponerlo en práctica e implementarlo, adoptada por el órgano de administración, no puede dejar de valorarse al momento de juzgar la responsabilidad penal de éste por los delitos que, pese a todo, pudieran haberse cometido en el ámbito empresarial. Menos puede dejar de valorarse si se tiene en cuenta que, con la implantación de un programa de cumplimiento idóneo, es la propia empresa quien detecta el delito y lo comunica luego a las autoridades competentes.

La implantación de un programa de cumplimiento ex ante eficaz genera pues, como consecuencia, la exclusión o la atenuación de la responsabilidad penal de los órganos de administración ${ }^{32}$, en caso tenga lugar la comisión de un delito. Si el programa de cumplimiento no se mostrara eficaz ex ante, la infracción del deber de vigilar igualmente habrá tenido lugar, pudiendo fundamentarse la responsabilidad penal en la implantación de un programa de cumplimiento insuficiente o en la implementación insuficiente del mismo ${ }^{33}$.

Si bien el implantar un programa de cumplimiento genera consecuencias distintas sobre la responsabilidad penal de los directivos, según se trate de delitos cometidos contra la empresa - posición de garante ad intra-o de delitos cometidos desde ésta en perjuicio de terceros - posición de garante ad extra- ${ }^{34}$, en la medida en que aquí interesa esta última dimensión y que aquí se pretende también incidir en el deber de vigilancia del superior sobre los subordinados, me centraré entonces en la responsabilidad penal que pudiera corresponder a los directivos por los delitos cometidos desde la empresa por sus dependientes.

Como dije, aunque en el caso peruano los directivos, en general, no tienen el deber jurídico-penalmente reforzado de implantar un Compliance program, sí tienen el deber de evitar lesiones incluso en otros ámbitos ${ }^{35}$, los de sus subordinados, por eso, como necesario correla-

32. En estricto, la implantación de un programa de cumplimiento puede tener también efectos eximentes o atenuantes para la persona jurídica. Respecto de la exención de pena, MATUS ACUÑA, Jean Pierre. "La certificación de los programas de cumplimento". En: ARROYO ZAPATERO, Luis y NIETO MARTíN, Adán (Dirs.). El Derecho penal económico en la era Compliance. Valencia: 2013, p. 152 y ss. Rechaza esta consecuencia, incluso en el caso de programas de cumplimento certificados, entre otras razones, porque las certificaciones, más que condiciones para eximir de pena, han se der consideradas condiciones para operar un negocio y porque las certificaciones, en la medida en que las paga quien luego las alega, no están libres de cuestionamientos.

33. Cfr. SIEBER. El Derecho penal económico en la era Compliance. Pp. 91 y ss.

34. Sobre el particular, SILVA SÁNCHEZ, Jesús María. Fundamentos del Derecho penal de la Empresa. Madrid: 2013, p. 156. Señala que la posición de garantía de los administradores tiene una doble dimensión: una dimensión ad intra, orientada a la evitación de resultados lesivos para la propia empresa, que hace del administrador un garante de protección - Beschützergarant-y una dimensión ad extra, orientada a la evitación de resultados lesivos para personas externas a partir de la actividad de los miembros de la empresa, en cuya virtud el administrador aparece como un garante de control —-Sicherungs o bien Überwachungsgarant-.

35. En este sentido, Cfr. ROBLES PLANAS, Ricardo. "El responsable de cumplimiento ("Compliance officer») ante el Derecho penal. En: SILVA SÁNCHEZ, Jesús María (dir.). Criminalidad de empresa y Compliance: prevención y reacciones corporativas. Barcelona: 2013, p. 322. 
to a su libertad de organización empresarial, les corresponde el deber de vigilancia, que puede ser satisfecho, entre otros mecanismos, con la implantación de un programa de cumplimiento ex ante eficaz ${ }^{36}$. De esta manera, si un subordinado comete un delito desde la empresa, pese a que los directivos han implantado al interior un programa de cumplimiento idóneo, éstos no responderán penalmente porque se entiende que han hecho todo lo posible para evitar el ilícito y no lo han logrado. Así, cuanto mejor esté configurado el programa de cumplimiento, desde el punto de vista de la prevención de infracciones, será menos probable poder impedir o dificultar el delito $y$, en consecuencia, menor la responsabilidad jurídico-penal del directivo ${ }^{37}$. En otras palabras, la existencia de un programa de cumplimiento ex ante eficaz se ha de valorar como prueba de que el directivo ha cumplido su deber de vigilancia.

Antes señalé que existen deberes delegables y que el instituto de la delegación hace surgir nuevas posiciones de garante. La mecánica puede ser la siguiente: en un primer momento, el empresario delega la coordinación y ejecución de ciertas tareas. Esta delegación hace que su posición de garante mute y no le corresponda ya controlar directamente las fuentes de riesgo que se encuentran en el ámbito de competencia del delegado; pero sí, entre otros deberes, el de vigilar la actividad de éste. En un segundo momento, el empresario, que tras la delegación conservaba el deber de vigilancia, delega a su vez este deber. Esta segunda delegación hace que su posición de garante vuelva a mutar y no le corresponda ya un deber de vigilancia activo - que le obligaba a vigilar a quienes ejecutan la tarea- sino un deber de vigilancia pasivo - que le obliga a mantener cierto grado de comunicación con quienes ejecutan materialmente las tareas de vigilancia y a intervenir en caso estos le comuniquen la concurrencia de una situación de peligro ante la que debe actuar- ${ }^{38}$. Evidentemente, al empresario le puede corresponder una responsabilidad penal si, pese a la delegación efectuada del deber de vigilancia, infringió alguno de los deberes residuales como el de seleccionar a persona idónea para la ejecución de ese deber.

De esta forma, el deber de vigilancia, que corresponde a los superiores jerárquicos, puede ser transferido por estos a un tercero -individual o pluripersonal; a saber: un específico departamento interno o una organización externa especializada en la materia ${ }^{39}$, según el tamaño de la empresa-. En este sentido, los directivos pueden delegar la gestión del programa de cumplimento a un oficial de cumplimiento. Dicho de otro modo, la instauración de un Compliance program en una empresa significa el surgimiento de una posición de garante en el sujeto a quien el superior jerárquico encargará los controles que dicho programa incorpora. Evidentemente, la infracción de este deber de vigilancia puede generar la responsabilidad penal de su titular: el oficial de cumplimiento.

Esta última afirmación no genera mayor debate cuando el propio legislador impone la obligación de encargar a un funcionario la gestión del Compliance program. Ello porque la ley, al asignarle un concreto ámbito de organización, es

36. Como los programas de cumplimiento constituyen uno de los mecanismos de los que disponen el directivo para cumplir su deber de vigilancia, DOPICO GÓMEZ-ALLER. El Derecho penal económico en la era Compliance. p. 168. Entiende que ese deber puede cumplirse incluso con mecanismos que no reúnan las características de un Compliance program.

37. En igual dirección, SIEBER. El Derecho penal económico en la era Compliance. p. 92.

38. Cfr. DOPICO GÓMEZ-ALLER. El Derecho penal económico en la era Compliance. p. 175.

39. El encargar el deber de vigilancia a un agente externo a la empresa tiene la ventaja de poder garantizar una mayor imparcialidad en el desempeño de sus funciones; no obstante, se le puede achacar un desconocimiento de las particularidades de la empresa específica. 
decir, específicos roles, hace nacer en el oficial de cumplimiento una posición de garantía que puede sustentar su responsabilidad penal por los delitos cometidos por los miembros de la empresa en ese concreto ámbito de competen$\mathrm{cia}^{40}$. Es fundamental que la responsabilidad penal se circunscriba al específico ámbito asignado porque si en la empresa existe un funcionario concreto a quien se encarga la prevención de un riesgo en particular, entonces es a este funcionario, y no al oficial de cumplimiento, a quien corresponde la responsabilidad penal, más allá de que al último de los nombrados competa el deber de coordinar con esos otros delegados y gestionar la información que le suministren.

El Compliance officer, en tanto delegado de vigilancia, gestiona el Compliance program. Esto significa que el propósito del oficial de cumplimiento va más allá de la mera ejecución de las concretas actividades de prevención. En estricto, su función consiste en desarrollar y mantener las políticas y los procedimientos internos orientados a que la empresa y su personal respeten las normas en la persecución de los objetivos corporativos.

El que corresponda al Compliance officer gestionar todas las medidas incorporadas en el programa de cumplimiento tiene como finalidad no solo corregir las conductas ilícitas detectadas sino también mejorar el Compliance program, haciéndolo más eficaz, a partir de la información que él pueda obtener sobre las falencias o limitaciones del programa. Respecto de esto último, como en una empresa pueden convivir el Compliance officer y otros delegados de vigilancia de sectores específicos, el oficial de cumplimento deviene en estos casos en un receptor de la información sobre las conductas defectuosas de- tectadas por estos otros delegados ${ }^{41}$. En buena cuenta, el Compliance officer se convierte en una suerte de intermediario entre el órgano superior jerárquico y los otros delegados sectoriales.

En líneas anteriores dije que la infracción del deber de vigilancia no es punible en sí misma, sino que la sanción al superior por infringir ese deber está marcada por la accesoriedad. Pues bien, siendo esto así, el Compliance officer solo responderá penalmente si un miembro de la empresa comete un delito doloso y si, respeto de este hecho, el oficial de cumplimiento infringió dolosamente su deber de vigilancia. En este orden de ideas, puesto que al oficial de cumplimiento le corresponde también actualizar o perfeccionar el Compliance program, si esta tarea no es ejecutada - o es retrasada o es realizada, pero de modo insuficiente-, pese a la existencia de recursos para tal fin, entonces en el delito concreto cometido por el subordinado concurrirá una intervención omisiva dolosa de aquél, bien a título de autor bien a título de partícipe, según las reglas explicadas anteriormente. De igual forma, se puede responsabilizar penalmente al Compliance officer si omitió su deber de vigilancia de forma imprudente. En este último supuesto, claro está, habrá que respetar las exigencias y las limitaciones inherentes a esa modalidad delictiva.

Para finalizar, se debe reconocer que, pese a lo señalado, la falta de homogeneidad de las funciones del oficial de cumplimiento, es decir, el que estas, más allá de algunas mínimas esenciales, varíen de una empresa a otra, dificulta investigar la responsabilidad de dicho funcionario por la no evitación de delitos cometidos en el ámbito empresarial ${ }^{42}$. En cualquier caso, la imputación de responsabilidad penal al oficial de cumplimiento

40. En el mismo sentido, GARCÍA CAVERO, Percy. Criminal Compliance. Lima: 2014, p. 106.

41. Cfr. SILVA SÁNCHEZ, Jesús María. Fundamentos del Derecho penal de la Empresa. Madrid: 2013, p. 199.

42. Para DOPICO GÓMEZ-ALLER. El Derecho penal económico en la era Compliance. pp. 168 y ss. La falta de uniformidad de las funciones del oficial de cumplimiento conlleva a que no se pueda generalizar sobre cuáles son los deberes que atañen a dicho funcionario. Por su parte, GARCÍA CAVERO, Percy. Criminal Compliance. Lima: 2014, p. 109. Parece no estar de acuerdo con esa falta de uniformidad pues afirma una trilogía de actividades que la literatura especializada atribuye al oficial de cumplimiento: labores de información, comunicación y capacitación; labores de asesoramiento a los miembros de la empresa en el ejercicio de sus actividades y labores de supervisión, control y reporte. 
exige establecer una conexión entre las funciones que se le han asignado y el concreto delito cometido, es decir, el juicio de responsabilidad ha de partir siempre por comprobar que la observancia estricta de las funciones asignadas habría evitado o al menos dificultado la ejecución del delito del miembro de la empresa ${ }^{43}$.

\section{CONCLUSIONES}

1. Los superiores jerárquicos son garantes respecto de la conducta de sus subordinados. Esto significa que tienen el deber de evitar que éstos, en el ejercicio de sus funciones, afecten bienes jurídicos de personas ajenas a la empresa. En este sentido, la posición de garante del directivo incluye el deber de vigilancia. La reducción o - incluso- la anulación de los frenos inhibitorios, consecuencias de la actuación en grupo, justifican la existencia en el superior del deber de vigilar. El deber de vigilancia es delegable.

2. La omisión del superior del deber de vigilancia puede dar lugar a la responsabilidad penal de éste, bien a título de autor bien a título de partícipe. La sanción al superior por esa omisión está marcada por la accesoriedad.

3. Los Compliance programs son herramientas de vigilancia de la propia empresa, es decir, mecanismos de autovigilancia. Las medidas de autovigilancia empresarial no agotan los programas de cumplimiento pues éstos también suelen incluir medidas orientadas a incentivar su observancia por parte de los miembros de la empresa.

4. En nuestro país, el establecer medidas orientadas a prevenir delitos es una decisión que corresponde al directivo. Ahora bien, si el superior jerárquico omite implantar un Compliance program, pese a que despliega su actividad empresarial en un sector cuyas peculiaridades lo hacen necesario ex ante, puede ser pasible de una pena, si un subordinado comete un delito en el desempeño de sus funciones. En ese caso, su omisión habrá significado incumplir el deber de vigilancia.

5. Como no existe deber legal de implantar un Compliance program, el deber de vigilancia puede satisfacerse mediante la implantación de mecanismos alternativos a éstos. Así, en ámbitos empresariales no complejos la omisión del directivo de instaurar un Compliance program no significa una infracción de su deber de vigilancia, por eso tal comportamiento no da lugar a responsabilidad penal.

6. La implantación de un programa de cumplimiento ex ante eficaz genera la exclusión o la atenuación de la responsabilidad penal de los órganos de dirección, en caso tenga lugar la comisión de un delito. Así, si un subordinado comete un delito desde la empresa, pese a que se implantó un programa de cumplimiento idóneo, los directivos no responderán penalmente porque han hecho todo lo posible para evitar el ilícito y no lo han logrado.

7. El deber de vigilancia de los superiores jerárquicos puede ser transferido por éstos a un tercero: el oficial de cumplimento. El Compliance officer, en tanto delegado de vigilancia de la empresa, gestiona el Compliance program. Puesto que la delegación hace surgir una posición de garante en el oficial de cumplimiento, la omisión del deber de vigilancia puede acarrearle responsabilidad penal.

43. Esta forma de proceder evidencia que la imputación causal no es desplazada por la imputación objetiva sino que aquélla le sirve de base a ésta, complementándola. Por eso la determinación de si el aporte del oficial de cumplimiento al hecho delictivo corresponde al de un autor o al de un partícipe tiene lugar una vez establecida la conexión entre las funciones que se le han asignado y el concreto delito cometido. Respecto de esto último, Cfr. ROBLES PLANAS, en Criminalidad de empresa y Compliance. p. 328. 